\title{
Pengukuran Kinerja Karyawan Dengan Metode Human Resources Scorecard Dan AHP (Studi Kasus : PT. Bella Citra Mandiri Sidoarjo)
}

\author{
Abdul Rosyid Sahaya ${ }^{{ }^{*}}$, Hana Catur Wahyuni² \\ Universitas Muhammadiyah Sidoarjo \\ E-mail: \\ ${ }^{1}$ sahayarosyid@gmail.com, $\underline{{ }^{2} \text { hanacatur@umsida.ac.id }}$
}

\begin{abstract}
ABSTRAK
PT. Bella Citra Mandiri Sidoarjo merupakan perusahaan yang bergerak dibidang pembuatan tempat tidur springbed. PT. Bella Citra Mandiri Sidoarjo saat ini menata diri menjadi perusahaan yang lebih maju, sedang berusaha mengembangkan dan meningkatkan dari segi kualitas sumber daya manusianya.

Dengan metode Human Resource Scorecard dan AHP (Analytic Hierarchy Process) akan didapatkan pengukuran kinerja karyawan yang belum pernah dilakukan pada perusahaan ini. Metode Human Resources Scorecard sendiri merupakan suatu sistem pengukuran yang mengaitkan antara sumber daya manusia dengan strategi. Kemudian metode AHP digunakan dalam pengambilan keputusan kinerja karyawannya.

Tujuan dari penelitian ini adalah mencari indikator kinerja karyawan serta mencari bobot dari masing - masing perspektif. Serta diberikan usulan kepada perusahaan yang dapat digunakan sebagai perbaikan kedepannya.

Dari hasil penelitian didapatkan 18 KPI dari 4 perspektif yang terdiri dari perspektif finansial $4 \mathrm{KPI}$, pelanggan atau konsumen $3 \mathrm{KPI}$, proses bisnis internal $7 \mathrm{KPI}$, dan pertumbuhan dan pembelajaran $4 \mathrm{KPI}$. Kemudian dihasilkan skor terbobot dari perspektif finansial 3,341 (Sedang), pelanggan atau konsumen 3,524 (baik), proses bisnis internal 3,357 (sedang), pertumbuhan dan pembelajaran 3,38 (sedang).

Kata Kunci: Kinerja Karyawan, Human Resource Scorecard, Analytic Hierarchy Process, Key Performance Indicator
\end{abstract}

\section{ABSTRACT}

PT. Bella Citra Mandiri Sidoarjo is a company engaged in the manufacture of springbed. PT. Bella Citra Mandiri Sidoarjo is currently organizing into a more advanced company, Is trying to develop and improve in terms of the quality human resources.

With Human Resource Scorecard and AHP (Analytic Hierarchy Process) method, we will get employee performance measurement that has never been done in this company. The Human Resources Scorecard method is a measurement system that links human resources with strategy. Then the AHP method is used in employee performance decisions. 
The purpose of this study is to find employee performance indicators as well as looking for the weight of each perspective. And give advice to the company that can be made improvements in the future.

From the results of the study obtained $18 \mathrm{KPI}$ from 4 perspectives consisting of financial perspective $4 \mathrm{KPI}$, customer or consumer $3 \mathrm{KPI}$, internal business process $7 \mathrm{KPI}$, and growth and learning $4 \mathrm{KPI}$. Then generated weighted scores from financial perspective 3,341 (Medium), customer or consumer 3,524 (good), internal business process 3,357 (medium), growth and learning 3,38 (medium).

Keywords: Employee performance, Human Resource Scorecard, Analytic Hierarchy Process, Key Performance Indicator

\section{PENDAHULUAN}

PT. Bella Citra Mandiri Sidoarjo merupakan perusahaan yang bergerak dibidang pembuatan tempat tidur springbed. PT. Bella Citra Mandiri Sidoarjo saat ini menata diri menjadi perusahaan yang lebih maju, sedang berusaha mengembangkan dan meningkatkan dari segi kualitas sumber daya manusianya. Penelitian ini dilakukan pada devisi produksi, devisi ini merupakan salah satu area yang dalam permasalahan kinerja karyawan terdapat penurunan kinerja karyawan dikarenakan kurangnya motivasi kerja dari karyawan itu sendiri. Sering bolosnya karyawan dalam bekerja menjadi salah satu contoh kurangnya motivasi kerja pada karyawan. Serta tidak adanya jenjang karir yang menjadi salah satu permasalahan penurunan kinerja karyawan. Apabila kondisi seperti ini terus terjadi maka berdampak pada penurunan produktivitas perusahaan. Hal tersebut dapat menyebabkan perusahaan tidak melakukan perbaikan dalam kinerja karyawannya dan kondisi ini akan terjadi terus menerus.

Berdasarkan kondisi yang ada pada saat ini oleh karena itu, dibutuhkannya perbaikan pengukuran kinerja karyawaengan menggunakan metode Human Resources Scorecard. Dalam konsep Human Resources Scorecard sendiri agar perusahaan dapat mengolah tanggung jawab dan strategi secara efektif untuk menghadapi persaingan dimasa yang akan datang. Perusahaan ini dipilih karena belum pernah ada pengukuran kinerja karyawan dalam peningkatan sumber daya manusia.

Dari permasalahan tersebut, perlu dirancang suatu sistem pengukuran kinerja sistem sumber daya manusia dengan konsep Human Resources Scorecard pengukuran kinerja pada PT. Bella Citra Mandiri Sidoarjo untuk mengetahui gambaran yang akan dicapai pada sistem kinerja sumber daya manusianya. Human Resources Scorecard sendiri adalah suatu sistem alat pengukur sumber daya manusia yang mengaitkan strategi, kinerja dan manusia untuk mendapatkan hasil yang lebih unggul pada perusahaan.

Berdasarkan uraian pada latar belakang masalah tersebut, tujuan yang ingin dicapai pada pengukuran kinerja karyawan yaitu :

1. Menentukan indikator kinerja karyawan menggunakan metode Human Resources Scorecard.

2. Menentukan bobot masing-masing indikator kinerja karyawan pada PT. Bella Citra Mandiri Sidoarjo

3. Melakukan pengukuran kinerja karyawan pada PT. Bella Citra Mandiri Sidoarjo berdasarkan integrasi metode Human Resources Scorecard dan AHP (Analytic Hierarchy Process) 


\section{TINJAUAN PUSTAKA}

Pengukuran Kinerja

Arti dari pengukuran kinerja yaitu tindakan dalam pengukuran yang dilakukan kepada berbagai aktivitas yang terdapat pada suatu perusahaan dalam rantai nilai. Umpan baik yang digunakan dari hasil pengukuran tersebut, mendapatkan suatu informasi mengenai prestasi, melaksanakan rencana serta beberapa keperluan perusahaan dalam pengendalian dan penyesuaian (Mangkunegara, 2012). Pengukuran kinerja adalah suatu aktifitas yang secara terus menerus memonitor pencapaian program, terutama kearah kemajuan pencapaian tujuan jangka panjang (Susetyo, 2013).

\section{Human Resources Scorecard}

Sejak awal diperkenalkannya konsep Balance Scorecard oleh Kaplan dan Norton tahun 1992, konsepnya di Amerika sendiri telah diterapkan pada 200 perusahaan. Dalam perkembangannya, dominasi dari human capital dan modal intagible dari suatu organisasi menyebabkan metode Human Resources Scorecard ini dikembangkan. Human Resources Scorecard sendiri merupakan suatu sistem pengukuran yang mengaitkan antara sumber daya manusia dengan strategi, serta kinerja organik yang pada akhirnya mampu menimbulkan kesadaran tentang konsekuensi dalam keputusan investasi sumber daya manusia. Sehingga tepat arah dan tepat jumlah dalam keuntungan investasi sumber daya manusia(Queen, 2013).

Menurut Darmaji, 2016 Perspektif dalam Human Resources Scorecard dibagi menjadi 4 bagian yaitu:

1. Perspektif finansial adalah suatu aktivitas puncak dalam sebuah perusahaan apakah implementasi, pelaksanaan dan strategi perusahaan sudah memberikan kontribusi kepada perusahaan. Setiap departemen yang ada dalam perusahaan akan memberikan pertanggung jawaban untuk keadaan finansial perusahaan.

2. Dari segi perspektif pelanggan perusahaan harus memiliki relasi yang baik dengan konsumen. Dalam hubungan baik dengan pelanggan maka akan berdampak baik juga buat perusahaan. Implikasi dari adanya relasi dengan konsumen adalah reputasi perusahaan yang dikenal luas oleh pasar sehingga mampu menciptakan bargaining power yang besar.

3. Perspektif Proses Bisnis Internal bertujuan untuk mengidentifikasi setiap proses yang dilakukan serta mengembangkan metode pengukuran kerja yang memungkinkan sebagai proses kontrol. Dapat meningkatkan dan menjaga kinerja dari perusahaan itu sendiri.

4. Dalam Perspektif pertumbuhan dan pembelajaran proses belajar secara berkelanjutan oleh seorang pekerja seiring dengan bertambahnya pengalaman di tempat kerja. Proses pembelajaran dapat menjadi maksimal apabila iklim organisasi mendukung proses pembelajaran.

\section{KPI (Key Performance Indikator)}

Key Performance Indikator merupakan alat pengukuran yang digunakan sebagai pencapaian tujuan dalam menentukan derajat keberhasilan suatu organisasi atau perusahaan. Dalam kegunaanya pengukuran kinerja organisasi atau perusahaan dapat berupa keuangan atau tidak. Identifikasi dalam KPI dapat berupa keberhasilan dalam kegiatan, kesehatan dan pengembangan organisasi atau perusahaan, serta mewujudkan target organisasi dalam program atau penyampaian pelayanan. (Ulfa, 2015).

\section{AHP (Analytic Hierarchy Process)}

Dalam penemuan dan dikembangkannya AHP (Analytical Hierarchy Process) oleh Thomas L. Saaty. Merupakan pofesor matematika dari Universitas Pittsburg Amerika Serikat, pada tahun 1970-an. AHP merupakan suatu teori umum tentang pengukuran yang digunakan dalam menentukan skala rasio. Dalam perbandingan berpasangan yang diskrit ataupun 
kontinyu. Dalam masalah yang multi kriteria dan multi faktor AHP dapat menguraikannya secara kompleks sehingga menjadi suatu hirarki (Darmanto, 2014).

Saryatmo, 2015. AHP mempunyai input dasar dalam bentuk skala ratio. Dalam modelnya digunakan batas 1 sampai 9 yang dianggap cukup mewakili persepsi manusia. Seperti pada Tabel 1:

Tabel 1 Skala Persepsi

\begin{tabular}{|c|c|c|}
\hline $\begin{array}{l}\text { Tingkat } \\
\text { Ke-pentingan }\end{array}$ & Definisi & Keterangan \\
\hline 1 & $\begin{array}{l}\text { Sama } \\
\text { Kepentingannya }\end{array}$ & $\begin{array}{l}\text { Dalam kedua elemen memiliki pengaruh } \\
\text { yang sama }\end{array}$ \\
\hline 3 & $\begin{array}{l}\text { Sedikit Lebih } \\
\text { Penting }\end{array}$ & $\begin{array}{l}\text { Penilaian dan pengalaman sangat memihak } \\
\text { ke satu elemen dibanding dengan elemen } \\
\text { pasangannya }\end{array}$ \\
\hline 5 & Lebih Penting & $\begin{array}{l}\text { Satu elemen sangat disukai dan secara } \\
\text { praktis dominasinya sangat nyata. } \\
\text { Dibandingkan dengan elemen pasangannya }\end{array}$ \\
\hline 7 & Sangat Penting & Suatu elemen terbukti sangat disukai \\
\hline 9 & $\begin{array}{l}\text { Mutlak lebih } \\
\text { penting }\end{array}$ & $\begin{array}{l}\text { Satu elemen terbukti mutlak lebih disukai } \\
\text { dibandingkan dengan elemen pasangannya } \\
\text { pada keyakinan tertinggi }\end{array}$ \\
\hline $2,4,6,8$ & Nilai Tengah & $\begin{array}{l}\text { Diberikan bila terdapat keraguan penilaian } \\
\text { diantara dua tingkat kepentingan yang } \\
\text { berdekatan. }\end{array}$ \\
\hline
\end{tabular}

\section{METODOE PENELITIAN}

Adapun tahapan - tahapan dalam pengelolahan data sebagai berikut:

1. Tahapan awal dimulai dari identifikasi masalah, pada tahap ini dilakukan identifikasi masalah yang ada pada perusahaan.

2. Tahap kedua dilakukukan tahapan identifikasi KPI terhadap metode Human Resources Scorecard dimana KPI didapat dari 4 perspektif dalam metode ini. Pada kali ini pihak supervisior atau orang yang berkompeten pada bidangnya mempunyai peranan penting dalam pengambilan keputusan dalam menentukan KPI dalam setiap perspektif.

3. Data diawali dengan tahap pengisian responden kepada salah satu pihak Supervisor dari PT Bella Citra Mandiri Sidoarjo. Kuisioner yang digunakan yaitu kuisioner perbandingan berpasangan. Setelah data sudah terkumpul kemudian data di olah dengan bantuan Microsof Excel.

4. Dalam pembobotan metode yang digunakan yaitu AHP (Analytical Hierarcy Process) dimana metode ini digunakan untuk mengetahui prioritas bobot tingkat kepentingan 
masing masing indikator, dengan metode perbandingan berpasangan antara dua indikator sehingga semua indikator yang ada dapat tercakup.

5. Kemudian dalam kriteria pengukuran kinerja Skor yang terdapat pada penghitungan ini didapatkan dari hasil wawancara dengan pihak Supervisior PT. Bella Citra Mandiri Sidoarjo. Kriteria pengukuran kinerja karyawan dilakukan dengan acuan (Rusindiyatno, 2009) :

a. Untuk skor $\leq 1,8$ berarti kinerja karyawan sangat kurang.

b. Untuk skor $\leq 2,6$ berarti adalah kinerja karyawan kurang.

c. Untuk skor $\leq 3,4$ berarti adalah kinerja karyawan sedang.

d. Untuk skor $\leq 4,2$ berarti adalah kinerja karyawan baik.

e. Untuk skor $\leq 5,0$ berarti adalah kinerja karyawan sangat baik

\section{HASIL PENELITIAN DAN PEMBAHASAN}

Penentuan Key Performance Indicator (KPI)

Key Performance Indicator merupakan salah satu acuan pengukuran kinerja karyawan pada suatu perusahaan, dalam penelitian ini sudah ditetapkan KPI yang telah melalui pendekatan dengan metode Human Resource Scorecard. Terdapat 4 perspektif dalam metode ini dan mengidentifikasi sebanyak 18 KPI yang dapat dilihat pada tabel 2.

Tabel 2 Key Performance Indicator

\begin{tabular}{|c|c|c|c|}
\hline Prespektif & Kode & Key Performance Indicator & Kode \\
\hline \multirow{4}{*}{ Finansial } & \multirow{4}{*}{$\mathrm{F}$} & Presentase peningkatan pendapatan karyawan & F1 \\
\hline & & Presentase jumlah peningkatan produksi & $\mathrm{F} 2$ \\
\hline & & Efisiensi biaya tenaga kerja & F3 \\
\hline & & Efektifitas penggunaan anggaran pelatihan & F4 \\
\hline \multirow{3}{*}{$\begin{array}{l}\text { Pelanggan } \\
\text { atau } \\
\text { Konsumen }\end{array}$} & \multirow{3}{*}{ PK } & Jumlah komplain yang masuk dan terselesaikan & PK1 \\
\hline & & Kecepatan dalam pelayanan & PK2 \\
\hline & & Meningkatkan tanggung jawab karyawan & PK3 \\
\hline \multirow{7}{*}{$\begin{array}{l}\text { Proses Bisnis } \\
\text { Internal }\end{array}$} & \multirow{7}{*}{ PBI } & Presentase jumlah tingkat kehadiran karyawan & PBI1 \\
\hline & & Jumlah karyawan yang mengundurkan diri & PBI2 \\
\hline & & $\begin{array}{l}\text { Presentase jumlah karyawan yang sesuai } \\
\text { penempatan bidangnya }\end{array}$ & PBI3 \\
\hline & & $\begin{array}{l}\text { Jumlah karyawan yang sering telat dan tidak } \\
\text { masuk }\end{array}$ & PBI4 \\
\hline & & Jumlah keterlambatan pemberian gaji & PBI5 \\
\hline & & Presentase banyaknya data telah terkomputeriasi & PBI6 \\
\hline & & Meningkatkan motivasi kerja karyawan & PBI7 \\
\hline \multirow{4}{*}{$\begin{array}{l}\text { Pertumbuhan } \\
\text { dan } \\
\text { Pembelajaran }\end{array}$} & \multirow[t]{4}{*}{$\mathrm{PP}$} & Jumlah dan jenis pelatihan karyawan & PP1 \\
\hline & & Presentase pemenuhan dan permintaan karyawan & PP2 \\
\hline & & $\begin{array}{l}\text { Presentase pemahaman karyawan mengenai } \\
\text { MSDM }\end{array}$ & PP3 \\
\hline & & Peningkatan bonus dan reward tiap tahun & PP4 \\
\hline
\end{tabular}

\section{Perhitungan AHP}

Setelah didapatkan KPI dari masing - masing perspektif kemudian dilakukan perhitungan AHP. Pada tahap ini akan dihitung tiap perspektif yang nantinya diketahui bobot dari masing - masing perspektif. 


\section{Perbandingan Prioritas Perspektif Finansial}

Tabel 3 Pengukuran Kinerja Karyawan Perspektif Finansial

\begin{tabular}{|c|c|c|c|}
\hline Finansial & Skor & Bobot Prioritas & $\begin{array}{c}\text { Skor } \\
\text { Terbobot }\end{array}$ \\
\hline F1 & 3 & 0,060 & 0,18 \\
\hline F2 & 3 & 0,449 & 1,449 \\
\hline F3 & 4 & 0,364 & 1,456 \\
\hline F4 & 2 & 0,128 & 0,256 \\
\hline \multicolumn{3}{|c|}{ Jumlah } & $\mathbf{3 , 3 4 1}$ \\
\hline
\end{tabular}

Dari hasil yang telah diperoleh Pengukuran Kinerja Karyawan Perspektif Finansial untuk F1 (Presentase peningkatan pendapatan karyawan) mendapatkan skor terbobot terendah yaitu 0,18 sedangkan F3 (Efisiensi biaya tenaga kerja) mendapatkan skor terbobot tertinggi yaitu 1,456. Serta hasil dari skor terbobot untuk perspektif finansial mendapatkan 3,341 berarti dapat dikategorikan kinerja karyawannya sedang.

\section{Perbandingan Prioritas Perspektif Pelanggan atau Konsumen}

Tabel 4 Pengukuran Kinerja Karyawan Perspektif Pelanggan atau Konsumen

\begin{tabular}{|c|c|c|c|}
\hline $\begin{array}{c}\text { Pelanggan atau } \\
\text { Konsumen }\end{array}$ & Skor & Bobot Prioritas & $\begin{array}{c}\text { Skor } \\
\text { Terbobot }\end{array}$ \\
\hline PK1 & 4 & 0,633 & 2,532 \\
\hline PK2 & 3 & 0,260 & 0,78 \\
\hline PK3 & 2 & 0,106 & 0,212 \\
\hline \multicolumn{3}{|c|}{ Jumlah } & $\mathbf{3 , 5 2 4}$ \\
\hline
\end{tabular}

Dari hasil yang telah diperoleh Pengukuran Kinerja Karyawan Perspektif Pelanggan atau Konsumen untuk PK3 (Meningkatkan tanggung jawab karyawan) mendapatkan skor terbobot terendah yaitu 0,212 sedangkan PK1 (Jumlah komplain yang masuk dan terselesaikan) mendapatkan skor terbobot tertinggi yaitu 2,532. Serta hasil dari skor terbobot untuk perspektif Pelanggan atau Konsumen mendapatkan 3,524 berarti dapat dikategorikan kinerja karyawannya baik.

\section{Perbandingan Prioritas Perspektif Proses Bisnis Internal}

Tabel 5 Pengukuran Kinerja Karyawan Perspektif Proses Bisnis Internal

\begin{tabular}{|c|c|c|c|}
\hline $\begin{array}{c}\text { Pelanggan } \\
\text { atau } \\
\text { Konsumen }\end{array}$ & Skor & $\begin{array}{c}\text { Bobot } \\
\text { Prioritas }\end{array}$ & $\begin{array}{c}\text { Skor } \\
\text { Terbobot }\end{array}$ \\
\hline PBI1 & 3 & 0,295 & 0,885 \\
\hline PBI2 & 2 & 0,058 & 0,116 \\
\hline PBI3 & 4 & 0,282 & 1,128 \\
\hline PBI4 & 3 & 0,071 & 0,213 \\
\hline PBI5 & 3 & 0,070 & 0,21 \\
\hline
\end{tabular}




\begin{tabular}{|c|c|c|c|}
\hline $\begin{array}{c}\text { Pelanggan } \\
\text { atau } \\
\text { Konsumen }\end{array}$ & Skor & $\begin{array}{c}\text { Bobot } \\
\text { Prioritas }\end{array}$ & $\begin{array}{c}\text { Skor } \\
\text { Terbobot }\end{array}$ \\
\hline PBI6 & 3 & 0,087 & 0,261 \\
\hline PBI7 & 4 & 0,136 & 0,544 \\
\hline \multicolumn{3}{|c|}{ Jumlah } & $\mathbf{3 , 3 5 7}$ \\
\hline
\end{tabular}

Dari hasil yang telah diperoleh Pengukuran Kinerja Karyawan Perspektif Proses Bisnis Internal untuk PB2 (Jumlah karyawan yang mengundurkan diri) mendapatkan skor terbobot terendah yaitu 0,116 sedangkan PB3 (Presentase jumlah karyawan yang sesuai penempatan bidangnya) mendapatkan skor terbobot tertinggi yaitu 1,128. Serta hasil dari skor terbobot untuk perspektif Proses Bisnis Internal mendapatkan 3,357 berarti dapat dikategorikan kinerja karyawannya sedang.

\section{Perbandingan Prioritas Perspektif Pertumbuhan dan Pembelajaran}

Tabel 6 Pengukuran Kinerja Karyawan Perspektif Pertumbuhan Dan Pembelajaran

\begin{tabular}{|c|c|c|c|}
\hline $\begin{array}{c}\text { Pertumbuhan dan } \\
\text { Pembelajaran }\end{array}$ & Skor & Bobot Prioritas & $\begin{array}{c}\text { Skor } \\
\text { Terbobot }\end{array}$ \\
\hline PP1 & 3 & 0,210 & 0,63 \\
\hline PP2 & 4 & 0,481 & 1,924 \\
\hline PP3 & 3 & 0,210 & 0,63 \\
\hline PP4 & 2 & 0,098 & 0,196 \\
\hline \multicolumn{3}{|c|}{ Jumlah } & $\mathbf{3 , 3 8}$ \\
\hline
\end{tabular}

Dari hasil yang telah diperoleh Pengukuran Kinerja Karyawan Perspektif Pertumbuhan dan Pembelajaran untuk PP4 (Peningkatan bonus dan reward tiap tahun) mendapatkan skor terbobot terendah yaitu 0,196 sedangkan PP2 (Presentase pemenuhan dan permintaan karyawan) mendapatkan skor terbobot tertinggi yaitu 1,924. Serta hasil dari skor terbobot untuk perspektif Pertumbuhan dan Pembelajaran mendapatkan 3,38 berarti dapat dikategorikan kinerja karyawannya sedang.

Setelah dilakukan pengukuran skor terbobot antara setiap KPI dapat dilihat skor terbobot masing - masing dalam struktur hirarki pada gambar 1 
Gambar 1 Struktur Hierarchy Terbobot

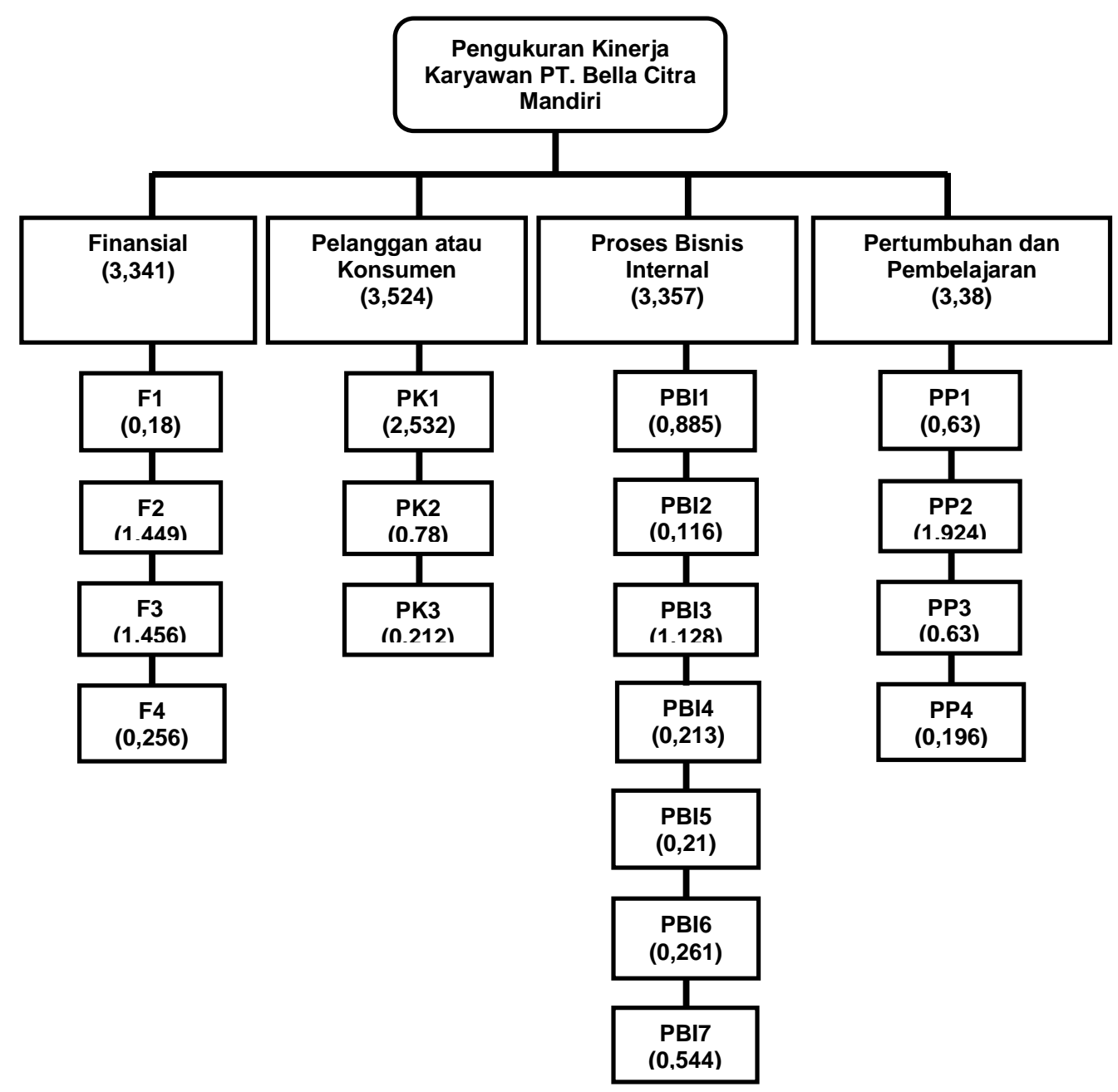

\section{KESIMPULAN}

Berdasarkan hasil dari penelitian yang telah dilakukan pada bab 4, maka hasil dari penelitian ini dapat disimpulkan bahwa pengukuran kinerja karyawan di PT. Bella Citra Mandiri Sidoarjo yang mengacu pada tujuan penelitian didapatkan kesimpulan sebagai berikut :

1. Indikator kinerja karyawan pada PT. Bella Citra Mandiri Sidoarjo menghasilkan 18 KPI yang terdiri dari Perspektif Finansial sendiri terdapat 4 KPI, Perspektif Pelanggan atau Konsumen terdapat 3 KPI, Perspektif Proses Bisnis Internal terdapat 7 KPI, Perspektif Pertumbuhan dan Pembelajaran terdapat 4 KPI.

2. Dari hasil pembobotan yang telah dilakukan peneliti menggunakan metode Analitycal Hierarchy Process (AHP) menghasilkan untuk Perspektif Finansial hasil pembobotan KPI mendapatkan jumlah skor terbobot 3,341 berarti dapat dikategorikan kinerja karyawannya sedang. Perspektif Pelanggan atau Konsumen hasil pembobotan KPI mendapatkan jumlah skor terbobot 3,524 berarti dapat dikategorikan kinerja karyawannya baik. Perspektif Proses Bisnis Internal hasil pembobotan KPI mendapatkan jumlah skor terbobot 3,357 berarti dapat dikategorikan kinerja karyawannya sedang. Perspektif Pertumbuhan dan Pembelajaran Hasil pembobotan KPI mendapatkan jumlah skor terbobot 3,38 berarti dapat dikategorikan kinerja karyawannya sedang. 


\section{REFERENSI}

Agusman, Delfis. dkk. 2013. Manajemen Sistem Kerja Untuk Peningkatan Kinerja Karyawan PT.CP. Jurnal Ilmiah Teknik Industri. Vol.1, No.2, 103-108.

Becker, Brian E. Dkk. 2009. The HR Scorecard: Mengaitkan Manusia, Strategi Dan Kinerja, Diterjemahkan Dian Rahadyanto Basuki. Erlangga. Jakarta.

Cahyono E.,D, Wahyuni H.C. 2015. Penilaian Teknologi Menggunakan Analytic Hierarcy Process Dan Teknometrik Di Departemen Produksi. Jurnal Ilmiah Teknik Industri, Vol.3,No.1. Universitas Pendidikan Ganesha. Singaraja

Darmaji, Kevin. 2016. Implementasi KPI dan Perancangan Sistem e-KPI pada PT. XYZ. Jurnal Titra, Vol. 4, No.2.

Darmanto, Eko. dkk. 2014. Penerapan Metode AHP (Analytic Hierarcy Process) Untuk Menentukan Kualitas Gula Tumbu. Jurnal SIMETRIS Vol.5 No.1.

Mangkunegara, Anwar Prabu. 2012. Evaluasi Kinerja SDM. PT Refika Aditama. Bandung.

Mayasari, Isti. dkk. 2012. Penilaian Kinerja Berdasarkan Kompetensi Dan Kpi (Key Performer Indicator) Perusahaan Daerah Air Minum Kabupaten Semarang. Kajian Ilmiah Psikologi Vol.1 No.2.

Prasetya, D.W. 2016. Pengukuran Kinerja Pegawai dengan Menggunakan Human Resources Scorecard (Studi Pada Kantor Kekayaan Negara dan Lelang Manado). Jurnal Riset Bisnis dan Manajemen. Vol.4 No.3.

Putri, Dyah Aisyah. 2015. Pengukuran Kinerja Karyawan PT. Pertamina (Persero) TBBM Semarang Group Dengan Pendekatan Human Resources Scorecard. Jurnal Teknik Industri. Vol.10, No.3.

Queen, Falah. 2013. Perancangan Sistem Pengukuran Kinerja Sumber Daya Manusia Dengan Pendekatan Human Resources Scorecard.Jurnal Teknik Industri Vol.1 No.4 Desember.

Rusindiyanto. 2009. "Analisis Kinerja Sumber Daya Manusia dengan metode Human Resources Scorecard (HRSC) (Studi kasus di PT. Arto Internasional Sidoarjo)", Jurnal Penelitian Ilmu Teknik Vol.9 No.2 Desember.

Saryatmo, Mohammad Agung. 2015. Penilaian Kinerja Customer Relationship Management Dalam Industri Perbankan Dengan Menggunakan Metode Analysis Hierarchy Process (Studi Kasus Pada Bank. XXX). Jurnal Ilmiah Teknik Industri Vol.3 No.2.

Susetyo, Joko. 2013. Penerapan Sistem Pengukuran Kinerja Perusahaan Dengan Metode Integrad Performance Measured System (IPMS) Pada PT.X. Jurnal Teknologi Vol.6 No.1 Juni.

Ulaila, Tia. 2014. Analisis Pengukuran Kinerja Rumah Sakit Al-Irsyad Dengan Pendekatan Balanced Scorecard. Jurnal Ilmu dan Riset Akutansi. Vol.3 No.7.

Ulfa, Maria. 2015. Analisis Pengukuran Kinerja Karyawan Dengan Metode Human Resource Scorecard di BMT Logam Mulia. Jurnal Ekonomi Syariah. Vol.3, No.2, Desember.

Wahyuni H.C, Ciptomulyono U, Supriyanto H. 2009. Analisa Tingkat Kecanggihan Humanware Dengan Pendekatan Teknometrik Di Pabrik Gula Candi Baru Sidoarjo. Prosiding Seminar Nasional Manajemen Teknologi x, Teknik Indusri Institut Teknologi Sepuluh November. Surabaya 